\title{
Durability behavior of prepainted steel sheet for construction
}

\author{
Huiping Bai ${ }^{1, a}$, Yuanqiang Tu, ${ }^{1, b}$, Rong $\mathrm{Du}^{1, \mathrm{c}}$, ,Zehong Lei ${ }^{1, \mathrm{~d}}$ \\ ${ }^{1}$ Research and development Center of WISCO, Wuhan 430080, China

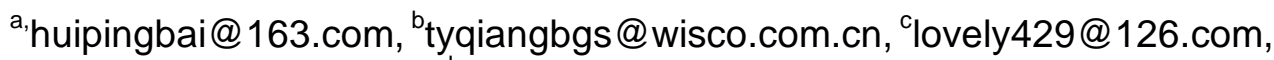 \\ leizehongxx@126.com
}

Keywords: prepainted steel sheet, construction, durability.

Abstract. The durability behavior of prepainted steel sheets for construction produced by different companies was studied by neutral salt spray analysis and accelerated UV ageing test with the aid of glow discharge optical emission spectrometry (GDS). The salt spray results suggested that both prepainted steel sheets possessed high corrosion resistance to neutral $\mathrm{NaCl}$ solution, in accordance with the demands of domestic and overseas standards. The corrosion protection of the sample produced by WISCO was higher than the other sample. The UV ageing results indicated that their UV radiation resistance could meet the national and European standards. What's more, the sample from WISCO had better ageing performance, getting to the highest grade $\mathrm{R}_{\mathrm{UV} 4}$. The reason was that the distribution of Ti pigment in greyish-white dope of WISCO's sample was more uniform and deeper.

\section{Introduction}

The prepainted steel sheets were also named with continuously organic coated steel flat products. They are coated with organic dope on the steel substrates such as continuously hot-dip zinc coated low carbon steel strips and electrolytically zinc coated steel strips. They possessed high corrosion resistance, ornamental appearance and friendly environmental effect. At present , almost 85\% prepainted steel sheets ${ }^{[1 \sim 4]}$ in China were used for construction which included building exterior applications such as ribbed profiles for roofing and walling, curved profiles, brake-pressed profiles, factory foamed sandwich panels, accessories, rainwater goods and metal doors and building interior applications such as components of the building fabric.

With the increasing demand for surface quality and performance of prepainted steel sheets, those presently produced by most private steel industries can not meet the purchasers' requirements on the corrosion and ageing protection. The corrosion attack such as glosslessness, color change, pulverization and rust happened on the surface of concerned building construction products after 2 or 3 years in service, especially on the processed regions. This was a great loss not only of money but also of human forces. So it is necessary for WISCO to develop this kind of prepainted sheets with higher corrosion and ageing resistance.

In this paper, the durability behavior of prepainted steel sheets for construction was studied by salt fog spray test and UV accelerated ageing test.

\section{Experimental}

The experimental materials were prepainted steel sheets for construction with the trademark TS250GD+Z, which were manufactured by Ma Steel and WISCO, naming sample $1^{\#}$ and $2^{\#}$ respectively. The metal material was hot-dip zinc coated low carbon steel strips with the zinc quantity of both sides was $120 \mathrm{~g} / \mathrm{m}^{2}$. The thickness of prepainted steel sheets was $0.80 \mathrm{~mm}$. The top side of these two samples was coated with greyish-white finishing coat with the coating thickness of $20 \mu \mathrm{m}$.

The resistance to neutral salt spray of the prepainted steel sheet was investigated by ST-ISO-3 salt fog spray box. The experimental temperature was controlled at $(35 \pm 2){ }^{\circ} \mathrm{C}$ and the electrolyte 
solution used in this work was $5 \% \mathrm{NaCl}$. The solution was prepared with analytical grade reagents and distilled water. The experimental materials were laid on shelves at an angle $30^{\circ}$ from vertical. The surface was marked by special scribed tools in accordance with EN 13523-8.

The ageing resistance was studied by UV 2000 ageing box. The experimental parameters was as follows: radiation intensity was $0.77 \mathrm{~W} /\left(\mathrm{m}^{2} \cdot \mathrm{nm}\right)$ and radiation wavelength was $340 \mathrm{~nm}$ with the circle mode of $8 \mathrm{~h}$ : $4 \mathrm{~h} \mathrm{UV}$ illumination with the black temperature $(60 \pm 3)^{\circ} \mathrm{C}$, then $4 \mathrm{~h}$ condensation with the black temperature $(40 \pm 3)^{\circ} \mathrm{C}$. The UV ageing test last $2000 \mathrm{~h}$ ( 250 cycles). The UV radiation resistance test was carried out in accordance with EN 13523-10.

The elements distribution such as $\mathrm{Si}, \mathrm{Ti}, \mathrm{Al}, \mathrm{P}, \mathrm{Mo}, \mathrm{C}$ and $\mathrm{N}$ of organic polymers with depth was analyzed with glow discharge optical emission spectrometry (GDS).

\section{Results and Discussion}

Salt spray results. The analysis result of the prepainted steel sheets after $500 \mathrm{~h}$ salt fog spray test was shown in Table 1 . In this work, the spray amount was controlled in $1.34 \mathrm{ml} /\left(80 \mathrm{~cm}^{2} \cdot \mathrm{h}\right)$. The assessment of undercreep distance of scribed marks and damage on unscribed area was in accordance with GB/T13448 and GB/T1766 respectively.

Table $1500 \mathrm{~h}$ Salt fog spray analysis result

\begin{tabular}{ccccc}
\hline \multirow{2}{*}{ Sample } & \multicolumn{2}{c}{ Undercreep Distance of Scribed } & \multicolumn{2}{c}{ Damage on unscibed area } \\
& DMAX & DAVERA & Blistering & Rust \\
\hline $1^{\#}$ & 2.0 & 1.0 & $0(\mathrm{~S} 0)$ & $0(\mathrm{~S} 0)$ \\
$2^{\#}$ & 1.0 & 0.5 & $0(\mathrm{~S} 0)$ & $0(\mathrm{~S} 0)$ \\
GB/T12754 $(480 \mathrm{~h})$ & - & - & $\leq 3\left(\mathrm{~S}_{2}\right)$ or $\leq 2\left(\mathrm{~S}_{3}\right)$ & - \\
EN10169-2 $(360 \mathrm{~h})$ & - & $\leq 2$ & $0(\mathrm{~S} 0)$ & -
\end{tabular}

P.S: DMAX: Maximum Distance; DAVERA: Average Distance

The salt spray results suggested that no blistering and no rust occured on the unscribed area and the undercreep length of scribed marks didn't excceed $2 \mathrm{~mm}$ for both samples. Both prepainted steel sheets possessed high corrosion resistance to neutral $\mathrm{NaCl}$ solution and their corrosion performance met the demands of domestic and European standards commendably. The undercreep distance of sample $2^{\#}$ was shorter compared with sample $1^{\#}$. The corrosion protection of sample $2^{\#}$ was higher than that of sample $1^{\#}$.

UV ageing test results. The analysis result of prepainted steel sheets after $2000 \mathrm{~h}$ UV radiation was demonstrated in Table 2.

The UV ageing results indicated that no pulverization and no blistering happened on the surface after $2000 \mathrm{~h}$ UV radiation for both samples. As far as sample $1^{\#}$ was concerned, the rate of retained gloss was $62.2 \%$ and $\Delta \mathrm{E}$ was 1.92 , locating in category $\mathrm{R}_{\mathrm{UV} 3}$. For sample $2^{\#}$, the rate of retained gloss was $87.1 \%$ and $\Delta \mathrm{E}$ was 1.88 , situating in category $\mathrm{R}_{\mathrm{UV} 4}$. Their ageing resistance could meet the national standard GB/T12754 and overseas standard EN10169-2. What's more, the sample $2^{\#}$ possessed better performance compared with sample $1^{\#}$.

Fig. 1 illustrated the change in $\Delta \mathrm{E}$ with $\mathrm{UV}$ ageing time. For sample $1^{\#}$, the color change $\Delta \mathrm{E}$ varied slightly in initial ageing stage. Before $800 \mathrm{~h}, \Delta \mathrm{E}$ was less than 0.54 . Between $800 \mathrm{~h}$ and 1600 $\mathrm{h}, \Delta \mathrm{E}$ varied rapidly and it increased from 0.54 to 1.57 . After $1600 \mathrm{~h}, \Delta \mathrm{E}$ varied slightly and it reached 1.92 at last. For sample $2^{\#}$, the color change $\Delta \mathrm{E}$ varied slightly before $1200 \mathrm{~h}$ and $\Delta \mathrm{E}$ was 
less than 0.50 . Between $1200 \mathrm{~h}$ and $1600 \mathrm{~h}, \Delta \mathrm{E}$ varied rapidly and it ranged from 0.50 to 1.48 . After $1600 \mathrm{~h}, \Delta \mathrm{E}$ varied slightly and it reached 1.88 finally.

Table 2 Analysis result after $2000 \mathrm{~h} \mathrm{UV}$ ageing test

\begin{tabular}{|c|c|c|c|c|c|}
\hline Sample & $\begin{array}{c}\text { Retained Gloss (RG) } \\
\text { Ratio }\end{array}$ & $\begin{array}{c}\text { Color change } \\
\qquad \mathrm{E}\end{array}$ & Grade & $\begin{array}{c}\text { Pulverization } \\
\text { Grade }\end{array}$ & $\begin{array}{c}\text { Blistering } \\
\text { Grade }\end{array}$ \\
\hline $1^{\#}$ & $62.2 \%$ & 1.92 & $R_{U V 3}$ & 0 & $0\left(S_{0}\right)$ \\
\hline $2^{\prime}$ & $87.1 \%$ & 1.88 & $\mathrm{R}_{\mathrm{UV} 4}$ & 0 & \\
\hline $\mathrm{GB} / \mathrm{T} 12754(600 \mathrm{~h})$ & - & - & & $\leq 1$ & $0\left(\mathrm{~S}_{0}\right)$ \\
\hline \multirow{4}{*}{ EN10169-2 $(2000 \mathrm{~h})$} & $\mathrm{RG}_{\min }, \%$ & $\Delta \mathrm{E}_{\max }$ & & \multirow{4}{*}{ - } & \multirow{4}{*}{ - } \\
\hline & 30 & 5 & $\mathrm{R}_{\mathrm{UV} 2}$ & & \\
\hline & 60 & 3 & $\mathrm{R}_{\mathrm{UV} 3}$ & & \\
\hline & 80 & 2 & $\mathrm{R}_{\mathrm{UV} 4}$ & & \\
\hline
\end{tabular}

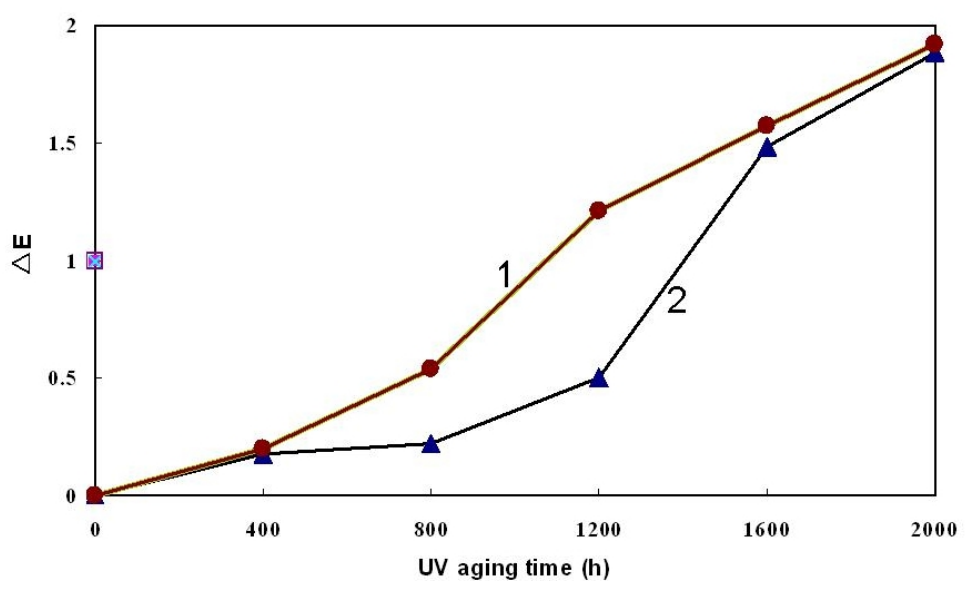

Fig.1 Change in $\Delta \mathrm{E}$ with $\mathrm{UV}$ ageing time

Discussion. Coil coatings to which pigments, additives and solvents have generally been added can provide protective, decorative and specific properties. The pigment, main part of the coil coating, can improve the liquidity of organic dope and elvate the intensity and the adhesion of coatings. The addition of pigments into organic polymers can not only make the coil coated steel flat products colorful and but also increase their corrosion and ageing resistance. Fig. 2 demonstrated the glow discharge optical emission spectrometry plots of prepainted steel sheets.

The results revealed that the Ti element came from the titanium pigment added into the greyishwhite finishing coat and the distribution depth of $\mathrm{Ti}$ was different. the Ti distribution depth of sample $1^{\#}$ was located in $6.6 \mu \mathrm{m}$ and the Ti distribution depth of sample $2^{\#}$ was located in $10.9 \mu \mathrm{m}$.

As an inorganic pigment, titanium pigment had higher contrast ratio of hiding power and better stability. It absorbed almost UV rays and had photocathode protection effect for metals under UV radiation ${ }^{[5]}$. Furthermore, the distribution of pigments has a great effect on the corrosion behavior of repainted steel sheets. The deeper distribution of $\mathrm{Ti}$ indicates the titanium pigment evenly spread around the greyish-white finishing coat and the coat was compact. The more compact finishing coat leads to higher corrosion resistance. 


\section{Summary}

The both prepainted steel sheets had good durability behavior.Sample $2^{\#}$ produced by WISCO possessed higher resistances to neutral salt fog and UV radiation compared with sample $1^{\#}$. This was because that the distribution of titanium pigment from greyish-white finishing coat of sample $2^{\#}$ was more uniform and deeper. The peak value of Ti in sample $1^{\#}$ was located in $6.6 \mu \mathrm{m}$ and the peak value of $\mathrm{Ti}$ in sample $2^{\#}$ was located in $10.9 \mu \mathrm{m}$.
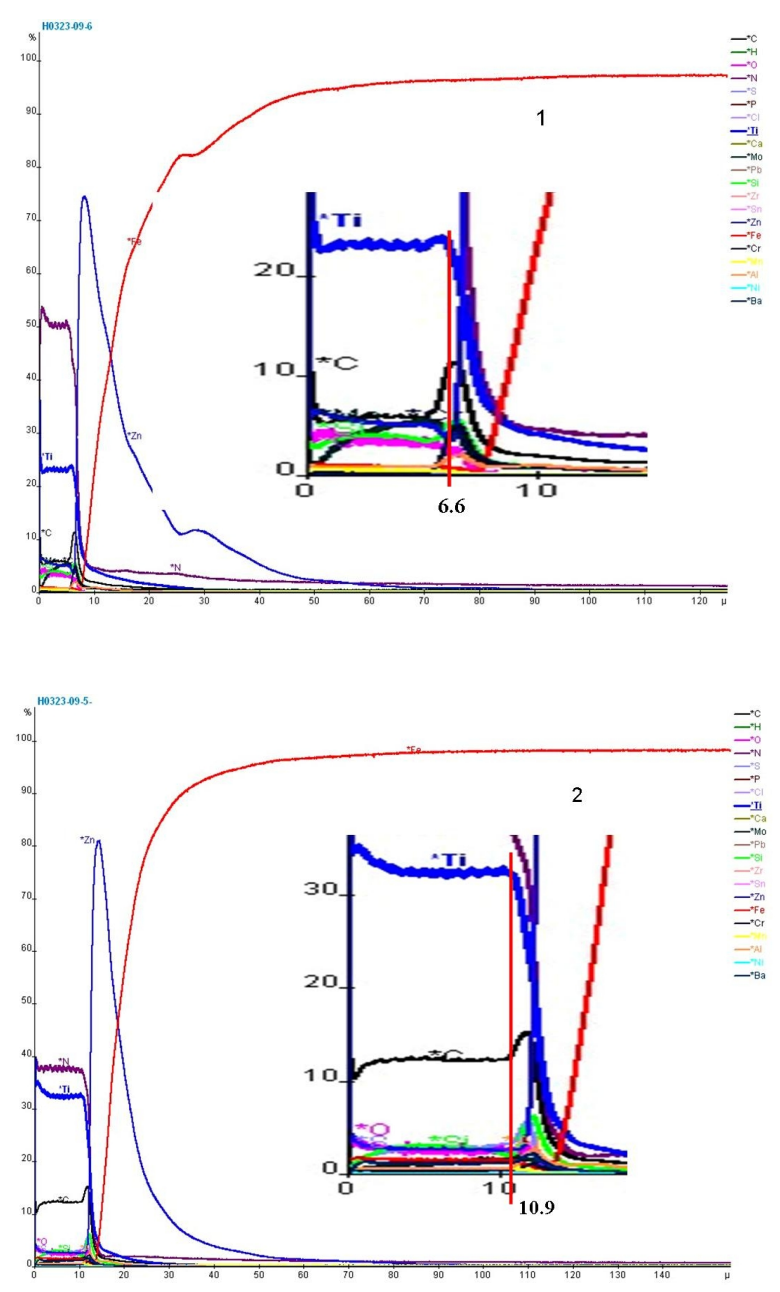

Fig.2 GDS plots of prepainted steel sheets

\section{References}

[1] Jia Song. China Metallurgical, Vol 4 (2002), P.26.

[2] Guoping Pan, Zhaolin Yang. Chinese Journal of Anhui Metallurgy, Vol 3 (2002), P.15.

[3] Yuansen Liang, Jianshe Xu, Yingqing Li etc. Chinese Journal of Sichuan construction Science Research, Vol 28, No.3 (2002), P.48.

[4] Daosui Tu, Xiaojing Wang. Chinese Journal of Iron \& Steel technology, Vol 4 (2008), P.19.

[5] Heng Zhang, Shaowei Bie, Jing Liu etc. The 4th Chinese Corrosion Meeting, 2003, P. 476. 